\title{
STUDIES ON HUMAN CAPILLARIES
}

\section{An Apparatus for Cinematographic Observation of Human Capiltaries}

\author{
By J. HAMILTON CRAWFORD AND HEINZ ROSENBERGER \\ (From the Hospital of the Rockefeller Institute for Medical Research, New York)
}

(Received for publication February 19, 1926)

Lombard (1) in 1911 showed that by illuminating the skin the capillaries could be seen under the microscope. Since then many observations have been carried out on the changes which take place in these vessels in health and disease. The early observations which were made recorded the impressions of the author but had no quantitative basis. In recent years photographic records have been made by some investigators in order to study the changes which take place in human capillaries. This method is suitable for recording gross changes which last for a considerable length of time, such as comparing the form of the capillaries in different diseased conditions. Many changes which take place in the capillary circulation are however rapid and so fleeting that it seemed desirable, if they were to be placed on a quantitative basis, to obtain records at a more rapid rate than one could do by ordinary photography. It seemed possible that cinematographic records would enable one to follow these changes and subsequently analyse them in detail by measurement.

The possibility of studying alterations in the capillaries by means of cinematography first suggested itself to Krogh and Rehberg (2). They developed a method of taking photographs of the circulation in the capillaries in the tissues of Rana temporaria. It is naturally simpler to obtain records from the tissues of frogs than from human tissues since for this purpose a technique resembling that used in histological photomicrography suffices. In the human case, however, transmitted light cannot be used, so Lombard's method of illumination from above has been universally adopted. This method is difficult because by it contrast and intensity of light are much reduced com- 
pared to these qualities obtained by transmitted light. The first photographs of human capillaries were taken by Weiss (3) in 1916. He devised an apparatus for accomplishing this end and published photographs obtained by his method in various diseased conditions. He used oblique' illumination and required an exposure of one to three quarters of a second to obtain satisfactory pictures. Siedentopf (Ziess) has devised an apparatus for the instantaneous photography of skin capillaries under normal conditions. In this apparatus also oblique illumination is used. More recently Sheard (4) has reported that he has been able to make photographs in rapid succession, but not cinematographic, of skin capillaries in the human subject. Here again oblique illumination was used but by momentarily increasing the intensity of the light at the time of the exposure, the exposure time was reduced to one tenth to one hundredth of a second. Callander (5) has also described a method which resembles those described above.

In the early stages of our work we also used oblique illumination and this was found to be satisfactory for ordinary photography but was not of sufficient intensity for cinematographic records. We therefore introduced a new feature in capillary microscopy, namely, vertical illumination. By this means a great conservation of light is obtained so that now it is possible to obtain satisfactory cinematographic pictures. These pictures are sharp and readily lend themselves to analysis by measurement. The purpose for which the apparatus was devised is in this manner fulfilled while in addition when the film is projected on the screen, the corpuscles can be seen to be in motion.

\section{THE APPARATUS}

The apparatus in its present form consists of five parts: (1) a bed and support for the arm, (2) a lighting system, (3) a microscope, (4) a stand for holding and adjusting the finger, and (5) a camera. Figure 1 shows the arrangement of the apparatus during an observation and figure 2 shows the optical system in more detail.

1. The bed and arm-holder. Carrier and Rehberg (6) have shown that changes take place in capillary pressure when the hand is held

1 The terms oblique and vertical refer to the incidence of the beam of light to the plane of the finger. 
at different levels below that of the heart. In order to obviate any changes due to this factor patients have been examined lying flat in bed with the arm extended horizontally at heart level. The arm is supported by an adjustable stand and fixed by sandbags. The height of the optical bench has been arranged so that the stand for holding the finger is on a level with the outstretched arm.

2. The optical system. The source of illumination is a 15 ampere direct current arc lamp with copper coated carbons (fig. 2, A). The

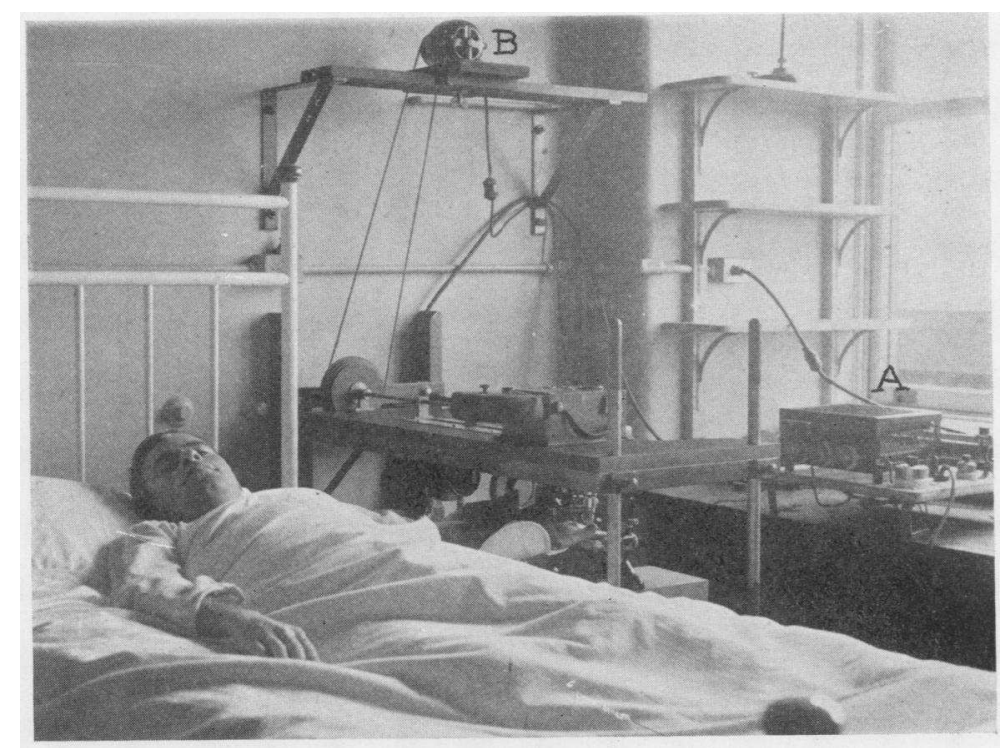

Fig. 1. Photograph of the Apparatus for Cinematographic PhotomiCROGRaphy OF tHe Capillaries of the NaJl Fold IN Human Subjects

intensity of the light is regulated by an adjustable resistance (fig. 1, $A$ ). The light from this passes through a powerful condensing system (fig. 2, $B B$ ) and also through a heat filter (fig. 2, C) which is situated between the two condensers. The light is thus focussed to a small point. It enters the system for direct illumination (fig. 2, D) and also passes through a polarizer. The latter has been introduced to prevent the reflection of light from the surface of the oil on the finger, which takes place with vertical illumination and prevents the capillaries 
from being seen. The polarizer (fig. 2, E) is attached to the receiving tube of the system for vertical illumination and the analyzer is situated in the tube of the microscope. With this illumination we have been able to obtain detail in our pictures to a degree which was impossible with oblique illumination. In order to learn whether the heat generated by the lighting system produced an increase in temperature at the finger we have made observations by placing a thermometer

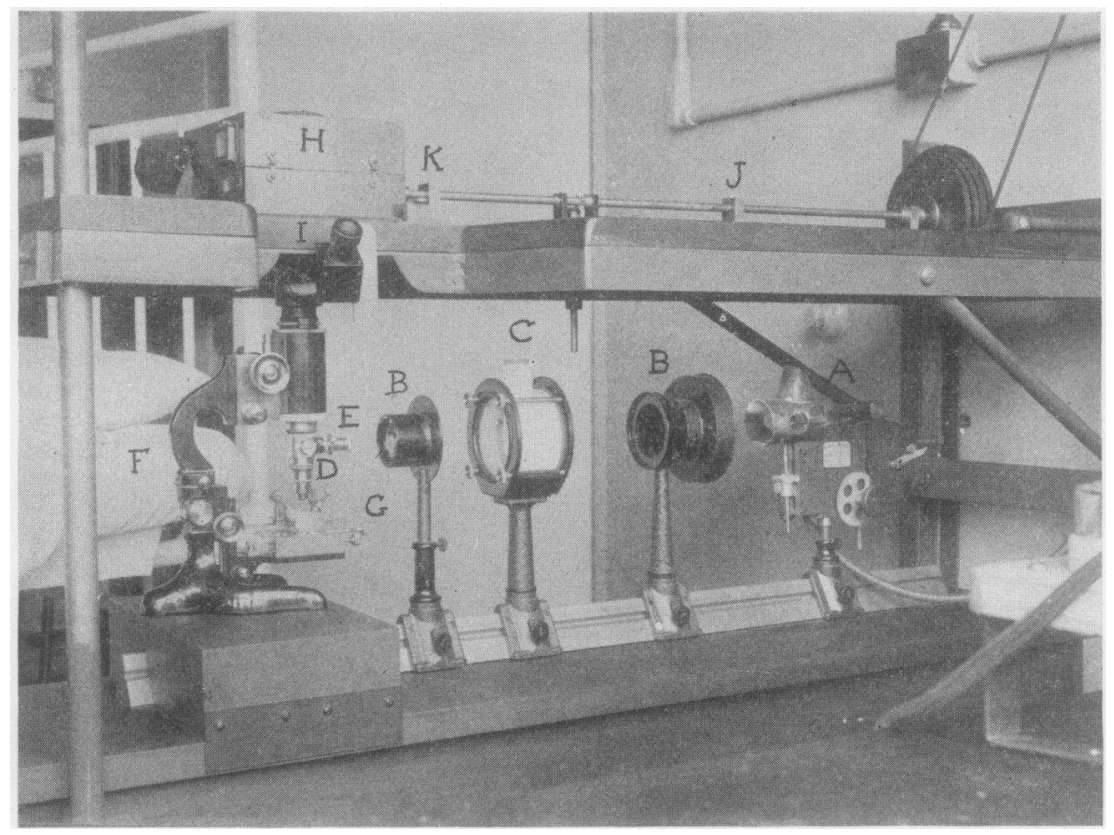

Fig. 2. Photograph Showing Detalls of the Apparatus for Cinematography of the CAPILlaRies

in its position. The technique was the same as that employed during the taking of pictures of the capillaries which is described below. The periods during which half strength and full strength of light were used were slightly in excess of those used in our longest observation. The temperature rose on the average $1.75^{\circ} \mathrm{C}$. during this period. The increase was practically constant in many observations. The greater part of the rise in temperature took place almost immediately, before the taking of the pictures was commenced. After the initial rise the 
increase was very slight and gradual. Methods of eliminating even this small rise of temperature are under investigation.

3. The microscope. In the microscopic system we use a Leitz metallurgic microscope (fig. $2, F$ ) with a moveable stage. The tube of the microscope is kept practically fixed and all focussing is managed by moving the stage of the microscope except the finest adjustment which is done by the micrometer screw on the microscope tube. A $16 \mathrm{~mm}$. apochromatic objective is used and no eye-piece. The tube of the microscope is as close as possible, without touching, to the stand which supports the camera. Through an opening in the stand on which the camera rests, there is a second short tube, the upper end of which fits the opening in the camera while the lower is telescoped into the tube of the microscope without touching it. This arrangement prevents the transmission to the microscope of any vibration caused by the mechanism of the camera. This system gives a magnification on the film of 14.4 times and has so far proved the most satisfactory arrangement.

4. The finger holder. The stand for the finger (fig. 2, $G$ ) has been constructed so that it is part of the stage of the microscope. The patient's finger is placed in a holder and fixed-without in any way interfering with the circulation in the finger-so as to avoid independent movement. Provision is made for adjustment in three directions by means of screws so that the finger can be placed in any desired position by the operator without voluntary movement on the part of the patient.

5. The camera (fig. 2, $H$ ) was devised specially for the purpose of cinematographic microphotography. The essential difference between it and the ordinary cinematographic camera is that it works in a horizontal plane and not vertically. The camera is situated on a special stand immediately above the microscope. On its upper surface there is a viewfinder by means of which the capillaries can be seen through the film. It is thus possible to control focussing during an observation so that the sharpest possible image can be obtained. Another method of focussing which we have used is the attachment of a Zeiss observation side piece (fig. 2, I) similar to that used in the Siedentopf apparatus, to the top of the tube of the microscope. In this arrangement it is provided that the distance from the prism 
which reflects the light to the eye is the same as that from the prism to the film. This method was easier than the other but a considerable amount of light was lost so that the pictures were not quite so satisfactory. We have recently reduced the amount of light passing out at the side piece and increased that to the film thereby obtaining equally satisfactory pictures. With experience however one can see the capillaries distinctly by the former method so that it has been used in most of our observations. The film is driven by a motor (fig. 1, B) which like the camera is on a separate stand and is operated by a foot switch. The speed of the motor is governed by a speedometer so that the number of exposures per second can be varied. The motor drives a shaft (fig. 2, $J$ ) which can be connected or disconnected with the camera by means of a clutch (fig. $2, K$ ).

The stands which support the motor, the camera,.and the optical

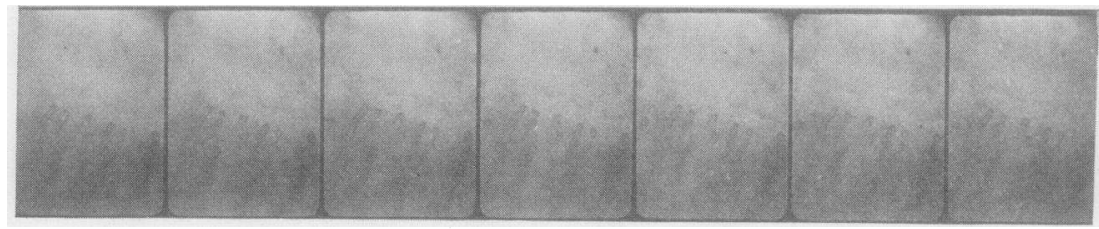

Fig. 3. Print of Part of a Cinematographic Film Taken by the Method DESCRIBED. $\times 14$

and lighting systems are in this arrangement all separate and in no way come in contact with one another. The transmission of vibrations from one to the other is consequently avoided.

\section{TECHNIQUE DURING AN OBSERVATION}

The patient lies flat in bed with the arm outstretched and the finger adjusted in the finger holder. The patient remains at rest in this position until the radial pulse has remained at a constant level for about five minutes. In cases where the pulse is irregular the observation does not begin until the variations are reduced to a minimum. Cedar wood oil is applied to the region to be examined. The light is now turned on half strength and the capillaries are brought into focus sharply on the film. The light is then turned on to the full capacity used and the motor which drives the film is started by pressing the foot 
switch. While the film is running the capillaries are kept under observation on the film and maintained sharply in focus by means of the fine adjustment on the microscope. The radial pulse is counted throughout the entire period. The temperature of the room is also noted. No estimations have been made of the capillary pressure as it did not appear that these observations would be of value in the problems involved in the present series of observations.

Satisfactory photographs can in this fashion be obtained (figure 3). The magnification on the film is only about 14 times but this image can be enlarged by means of a projectoscope to any desired magnification.

\section{CONCLUSION}

An apparatus is described by means of which it has been possible to take cinematographic records of the capillaries at the nail fold in the human subject.

\section{BIBLIOGRAPHY}

1. Lombard, W. P.: Amer. Jour. Physiol., 1912, xxix, 335. The Blood Pressure in the Arterioles, Capillaries and Small Veins.

2. Krogh, A., and Rehberg, P. B.: Amer. Jour. Physiol., 1924, lxviii, 153. Kinematographic Methods in the Study of the Capillary Circulation.

3. Weiss, E.: Deut. Arch. f. klin. Med., 1916, cxix, 1. Beobachtung und mikrophotographische Darstellung der Hautkapillaren am lebenden Menschen.

4. Sheard, C.: Science, 1924, lx, 409. Instantaneous Photomicrography of the Skin Capillaries in the Living Human Body.

Sheard, C., and Brown, G. E.: Jour. Lab. and Clin. Med., 1924-25, x, 925. A Method for Instantaneous Photomicrography of the Skin Capillaries

5. Callander, C. L.: Jour. Amer. Med. Assoc., 1925, lxxx, 352. Photomicrographic Studies of Morphology of Surface Capillaries in Health and Disease. 1. The Anatomy of Normal Surface Capillaries and a Photographic Method of Their Observation and Recording.

6. Carrier, E. B., and Rehberg, P. B.: Scand. Arch. f. Physiol., 1923, xliv, 20. Capillary and Venous Pressure in Man. 